\title{
Apresentação
}

\section{Políticas públicas, Estado e sociedade}

As políticas públicas constituem um dos principais resultados da ação do Estado. Contudo, algumas questões se impõem: por um lado, devemos nos perguntar se o Estado possui a legitimidade necessária para produzir efeitos no processo de políticas públicas. Com um mundo cada vez mais globalizado economicamente, o que significa dizer com atores institucionais do mercado cada vez mais potentes politicamente, e com uma sociedade civil que se diversifica tanto na sua agenda quanto na quantidade de atores relevantes, é previsível que esse cenário represente algum desafio adicional às tarefas estatais relacionadas à formulação e implementação de políticas.

Por outro lado, relacionado a esse contexto, aumenta o interesse em saber como se dá a relação entre os agentes estatais e demais atores nãoestatais, seja do mercado, seja da sociedade civil, na produção dessas políticas. Assistimos, nas últimas décadas, em praticamente todas as democracias contemporâneas, a um processo relativamente rápido de transferência de ativos controlados pelo Estado para as mãos dos agentes do mercado. Essa realidade deixou ainda mais evidente o fato de a autoridade separar-se institucionalmente da propriedade, como já observou Przeworsky. Essa separação crescente provoca não apenas uma redução na capacidade de intervenção do Estado, como também uma fonte adicional de tensão entre as principais esfe-

\begin{tabular}{|l|l|l|l|l|l|} 
Civitas & Porto Alegre & v. 5 & n. 1 & jan.-jun. 2005 & p. 5-9 \\
\hline
\end{tabular}


ras da sociedade. Assim como o caminho não está desimpedido para que os proprietários de capital definam os conteúdos das políticas, tampouco o Estado está em condições de implementar as políticas que mais lhe convêm, sem qualquer pressão externa. A razão para isso, já bastante bem explorada por Przeworky (em Estado e economia no capitalismo), é que, no capitalismo, a capacidade de formular e implementar não necessariamente anda junta, por dois motivos: por um lado, os governantes podem contar com a capacidade institucional de estabelecer seus próprios objetivos, mas podem encontrar obstáculos na implementação, devido à estrutura da economia, uma vez que a propriedade privada do capital implica que o Estado não comanda sozinho o investimento. Por outro lado, se o Estado possui a capacidade de intervir na economia, os agentes econômicos têm motivos suficientes para tentar se envolver com as políticas do Estado, já que serão afetados diretamente. Nesse sentido, quanto maior a capacidade do Estado de implementar suas preferências, menor tende a ser sua capacidade de formular políticas de forma independente.

Ao lado desse incremento da capacidade de atuação política dos atores econômicos, tem-se verificado, no Brasil, a consolidação de atores sociais como atores políticos relevantes, como bem expressam os trabalhos de Leonardo Avritzer e Sérgio Costa, dentre outros. Embora esses autores não coloquem em primeiro plano a capacidade de atores da sociedade civil de intervir diretamente na formulação de políticas públicas, as pesquisas empreendidas por ambos ajudam a entender a pressão a que estão submetidos os agentes estatais, de um lado para minimizar seu "ensulamento", de outro lado, para não se tornarem reféns de interesses econômicos robustos. Não há dúvida, contudo, que sempre haverá o risco desses interesses sociais se transformarem em mais um "cliente" do orçamento público, por meio das políticas governamentais, quando eles próprios se tornam objeto de tais políticas. O que importa aqui, no entanto, é perceber que os atores governamentais estão expostos cada vez mais a variadas frentes de negociação quando se trata de executar aquilo que, como foi dito, constitui um dos principais resultados de sua ação, que são precisamente as políticas públicas.

As questões mencionadas acima constituem precisamente o ponto de partida da presente edição da revista Civitas. Nosso interesse aqui é oferecer principalmente ao público das ciências sociais, estudantes e profissionais, uma série de artigos que tratam da temática referida acima, uns de forma 
mais direta e explícita que outros. Pretendemos, ademais, ampliar o leque de análise, teórico e empírico. No ensino das ciências sociais, raros são aqueles cursos que não abordam o tema das políticas públicas - quando o fazem exclusivamente sob o prisma da capacidade do Estado de formulá-las e implementá-las. Levando em consideração as transformações econômicas e políticas recentes, que provocam o surgimento ou o incremento da capacidade de ação política de atores não-estatais, a presente edição propõe então que tais atores sejam incorporados sistematicamente no escopo de análise das políticas públicas.

Com o intuito de consolidar esse tipo de debate, o Programa de PósGraduação em Ciências Sociais da PUCRS - em parceria com o British Council, o Goethe-Institut Porto Alegre, a Secretaria de Estado da Coordenação e Planejamento do Rio Grande do Sul e outras entidades - organizou em 2003 o III Seminário Brasil-Alemanha-Reino Unido Políticas Públicas e Sociedade. Também em 2003, esta abordagem das políticas públicas foi objeto de uma mesa-redonda e um grupo de trabalho durante o II Seminário Organização e Sociedade, promovido pelo PPGCS/PUCRS. A maioria dos artigos aqui publicados foi apresentada durante um dos dois seminários.

O artigo de Carlos Vasconcelos Rocha realiza um escrutínio da abordagem neoinstitucionalista, procurando identificar em sua análise a contribuição que esta corrente analítica teria a oferecer para a compreensão do processo de políticas públicas. Em especial, sua análise centra-se na discussão das idéias e da mudança institucional na formulação de políticas. Sua conclusão é de que, a despeito da contribuição que o neoinstitucionalismo oferece à compreensão empírica do processo em tela, suas limitações estariam localizadas na sua incapacidade de apresentar subsídios ao desenvolvimento de teorias para o entendimento da relação entre poder e políticas públicas.

O Professor Volker Schneider, da Universidade de Konstanz, Alemanha, é hoje uma das principais referências na literatura teórica e empírica sobre a constituição de redes de políticas públicas. Em seu artigo, Schneider se propõe a problematizar as redes de políticas públicas como uma alternativa na condução de sociedades complexas. De maneira bastante explícita, Schneider discute ambas as questões mencionadas acima, ou seja, a questão da legitimidade do Estado para dar efeito a suas decisões e a maneira como o Estado contemporâneo estabelece relações com os demais atores institucionais a fim 
de responder satisfatoriamente a este problema. $\mathrm{O}$ autor não deixa dúvidas quanto à qualidade da constituição de redes de políticas, quando se trata de sociedades mais complexas, tanto para a formulação de soluções para problemas sociais concretos quanto para colocar tais soluções em prática. Ao lado da discussão teórica apresentada por Schneider, destaca-se a representação gráfica de três diferentes redes de políticas públicas, construída a partir de pesquisas empíricas nos Estados Unidos e na Alemanha.

Na esteira dessa discussão, o artigo de Hermílio Santos aborda brevemente a possibilidade de constituição de redes de políticas públicas no Brasil. Destaca-se aqui a inclusão da discussão acerca do desenvolvimento da sociedade civil brasileira como uma condição indispensável para a concretização de redes de políticas públicas, não apenas nas áreas de política industrial e de serviços, como é recorrente na literatura internacional, mas também na implementação de políticas sociais. O artigo de Pedro Jaime, por sua vez, realiza uma discussão sobre o debate recente em torno da relação entre Estado e sociedade civil no Brasil, tendo como objetivo a realização de uma "etnografia do pensamento moderno" a partir da análise de dois livros publicados, um em 1997 e o outro em 2003, traçando um paralelo entre eles acerca das posições assumidas por diferentes atores sociais.

Já o artigo de Erni Seibel chama a atenção para uma área crítica para a sociedade brasileira nos dias atuais: as políticas de segurança pública. De acordo com a argumentação de Seibel estamos diante de indícios bastante concretos de que as sociedades contemporâneas se desincumbiram de sustentar o Estado de bem-estar social, optando por criar o que ele denomina de "estado prisional".

Thais Peres apresenta e discute a experiência do Programa Comunidade Solidária, um caso de política pública implementado durante o governo Fernando Henrique Cardoso, marcado pela articulação entre órgãos governamentais, a iniciativa privada e organizações não-governamentais. De acordo com Peres, essa inovação contribuiu para o processo de superação da tradição patrimonialista brasileira.

Michelle Stephanou aborda um tema pouco explorado pelas ciências sociais, mas que é crítico para a implementação de políticas públicas, ou seja, o financiamento dessas políticas. Parte significativa dos recursos para a execução de diversas políticas, notadamente em nível federal e estadual, é obtida 
junto às agências financiadoras multilaterais, dentre elas o Banco Internacional para Reconstrução e Desenvolvimento (BIRD) e o Banco Interamericano de Desenvolvimento (BID). Em seu artigo, Stephanou discute as metodologias de avaliação de políticas adotadas por ambas as agências, passo crucial para a renovação ou para a ampliação dos contratos de financiamento. A despeito de eventuais críticas que se possa fazer à atuação de tais bancos, a inclusão de suas metodologias de avaliação podem contribuir para o uso mais otimizado de parte desses recursos.

Os artigos de Agripa Faria Alexandre e de Paulo Ricardo da Rocha Araújo discutem políticas públicas setoriais de meio ambiente. De um lado, temos a discussão sobre o envolvimento de atores sociais na definição das diretrizes para o financiamento de políticas ambientais por meio do Fundo Nacional de Meio Ambiente. De outra parte, Paulo Araújo discute a relação do Estado com os demais espaços e atores sociais na definição de uma agenda de política ambiental, chamando a atenção para a emergência do que ele denomina de os "entornos eco-sócio-territoriais".

Vanessa A. de Souza e Alexandre Reis Rosa completam a presente edição propondo a discussão sobre a construção da identidade social para a recomposição de relações de trabalho. O fortalecimento de identidades sociais cumpriria o papel de contribuir para a recomposição do exercício da cidadania, principalmente daqueles grupos na sociedade que sofrem algum tipo de restrição no mundo do trabalho, o que pode significar a inclusão qualificada de suas percepções na melhoria das relações de trabalho.

Recorrente na maioria dos artigos aqui publicados é a inclusão nas discussões teóricas, bem como nas pesquisas empíricas, do papel de atores nãoestatais na produção de políticas. Trata-se de uma agenda que deverá ainda animar nossos debates acadêmicos e que já recebe atenção especial por parte daqueles envolvidos diretamente com a formulação e implementação de políticas públicas. O que ora se publica pretende ser uma contribuição a esse debate.

Hermílio Santos 